CARDIOVASCULAR MEDICINE

\title{
Cost of an emerging epidemic: an economic analysis of atrial fibrillation in the UK
}

\author{
S Stewart, N Murphy, A Walker, A McGuire, J J V McMurray
}

Heart 2004;90:286-292. doi: 10.1136/hrt.2002.008748

See end of article for authors' affiliations

....................

Correspondence to: Professor J McMurray, Department of Cardiology, Western Infirmary, Glasgow G11 6NT, UK j.mcmurray@bio.gla.ac.uk

Accepted 22 May 2003

\begin{abstract}
Objective: To evaluate the cost of atrial fibrillation (AF) to health and social services in the UK in 1995 and, based on epidemiological trends, to project this estimate to 2000.

Design, setting, and main outcome measures: Contemporary estimates of health care activity related to AF were applied to the whole population of the UK on an age and sex specific basis for the year 1995. The activities considered (and costs calculated) were hospital admissions, outpatient consultations, general practice consultations, and drug treatment (including the cost of monitoring anticoagulant treatment). By adjusting for the progressive aging of the British population and related increases in hospital admissions, the cost of AF was also projected to the year 2000.

Results: There were 534000 people with AF in the UK during 1995. The "direct" cost of health care for these patients was $£ 244$ million ( $€ 350$ million) or $0.62 \%$ of total National Health Service (NHS) expenditure. Hospitalisations and drug prescriptions accounted for $50 \%$ and $20 \%$ of this expenditure, respectively. Long term nursing home care after hospital admission cost an additional $£ 46.4$ million ( €66 million). The direct cost of AF rose to $£ 459$ million ( $€ 655$ million) in 2000 , equivalent to $0.97 \%$ of total NHS expenditure based on 1995 figures. Nursing home costs rose to $£ 111$ million ( €160 million).

Conclusions: AF is an extremely costly public health problem.
\end{abstract}

A trial fibrillation $(\mathrm{AF})$ is the most common of chronic cardiac arrhythmias. ${ }^{12}$ Approximately 1 in 100 of the population have $\mathrm{AF}$, though the prevalence rises to more than 1 in 10 in the elderly. ${ }^{1-4}$ The prevalence of AF is rising $^{4}$ and will continue to rise for the foreseeable future. ${ }^{1-4}$ The reason for this increase is twofold. Firstly, the population is aging rapidly, increasing the pool of people most at risk of developing AF. ${ }^{5}$ Secondly, survival from underlying conditions closely associated with AF, such as hypertension, coronary heart disease, and heart failure, is also increasing. ${ }^{6-8}$

Most patients with AF require long term pharmacological treatment, often including warfarin. ${ }^{9}$ Monitoring anticoagulant treatment is expensive. AF also leads to hospitalisation ${ }^{10-11}$ and is a cause of particularly costly cardiovascular morbidity-that is, stroke and heart failure. ${ }^{12-14}$ The number (and rate) of AF related hospitalisations (both primary and secondary) has increased twofold to threefold in recent years. ${ }^{15-18}$

Consequently, AF is likely to impose a substantial and growing economic burden on health care systems. This burden has never been quantified. The goal of this study was, therefore, to evaluate the direct cost of AF to the National Health Service (NHS) in the UK.

\section{METHODS}

A prevalence based approach was used to estimate the economic burden of AF. Contemporary data were obtained from epidemiological studies, government datasets, and other sources to estimate prevalence, health care utilisation, and costs. These data were applied, on an age and sex specific basis, to official mid year population estimates for the UK. The cost of AF was first calculated for 1995-the point in time when the most accurate data were available. The cost of $\mathrm{AF}$ in year 2000 was then calculated from a combination of contemporary and extrapolated data. To be consistent with previous analyses of this type, ${ }^{14}{ }^{19}$ where a range of estimates was available, we have used the most conservative alternative.

\section{Community based health care \\ Patient population}

Age and sex specific population prevalences of AF, derived from three cross sectional studies in the UK, were applied to the whole population for the year 1995. ${ }^{2021}$ These rates are approximately 10\% lower than the 1994 prevalence reported by the British general practice research database. ${ }^{4}$

\section{General practitioner consultations}

Age and sex specific rates of general practitioner consultations per 1000 population were obtained from the Information and Statistics Division (ISD) of the NHS in Scotland..$^{22}$ The ISD routinely collates and validates data from a number of general practices serving a representative sample of the Scottish population ( 51 practices at the time of this analysis). An age and sex specific adjustment was made to these data to take account of consultations in which AF was important but was not the recorded cause of consultation (only one was allowed). We used the same ratio as principal to secondary discharge diagnoses. We also assumed that 1 in 10 consultations took place in the patient's home. This assumption is in keeping with a formal analysis of the pattern of general practitioner visits in the $\mathrm{UK}^{23}$ but is likely to be conservative given the typically older cohort of patients with AF.

General practice referrals to an outpatient clinic We could find no information on hospital referral rates from primary care. However, as approximately one third of men and one quarter of women with AF are prescribed warfarin, ${ }^{4}$ we concluded that most of these patients would have had a specialist assessment at hospital-that is, 30\% of patients with $\mathrm{AF}$ are referred to an outpatient clinic (average two visits a year). 


\section{Drug prescriptions}

Prescribing data are available from the General Practice Research Database (211 practices in England and Wales) and smaller studies. ${ }^{44}$ Intercontinental Medical Statistics Ltd also monitor the prescribing patterns of 500 general practitioners from around the UK (P Stephens, personal communication, 2000/2001). We assumed a rate of seven prescriptions for each patient every year. On the basis of recent studies, we assumed that each of these patients would require eight visits to an anticoagulant clinic yearly. ${ }^{324}$

\section{Hospital based health care}

Hospital admissions

Hospitalisation rates for AF (principal and secondary discharge codings) were obtained from the ISD. ${ }^{16}{ }^{25}{ }^{26} \mathrm{Up}$ to six discharge diagnoses are coded (according to the Manual of the international statistical classification of diseases, injuries and causes of death, 9th revision (ICD-9) in 1995). The ICD-9 code for AF was 427.3..$^{27}$ The term "discharge" refers to live discharges and deaths. Subsequent hospitalisations for a patient can be identified on this linked database. These data are also linked through the General Register Office for Scotland to all deaths in the UK. Information on length of hospital stay (including ward speciality) and destination of live discharges (for example, to a nursing home) is also available.

These data were applied on a sex and age specific basis to the whole British population.

\section{Post-discharge outpatient clinic visits}

We assumed that after admission with a principal diagnosis of $\mathrm{AF}$, each "live discharge" not requiring subsequent long term care would lead to an average of three follow up hospital outpatient visits.

\section{Long term care}

We estimated the total number of days of admission to nursing homes from the proportion of patients directly discharged to such facilities (principal discharge diagnosis of AF only). A rolling average of the number of patients discharged to nursing homes each month and their duration of stay there (adjusted for the number of days remaining in that year, subsequent days of hospitalisation, and death) was calculated for 1995 .

\section{Information on costs related to AF in 1995 Community based health care}

The average cost of a general practitioner consultation was taken from an analysis of health care costs in the UK during 1995. ${ }^{28}$ Scottish health care costs for 1995/96 were used to obtain the cost of a visit to a hospital outpatient clinic (see below). ${ }^{19}$ The cost of drug specific prescriptions was obtained from Intercontinental Medical Statistics Ltd. A 10\% dispensing cost was added. These costs were cross checked with government prescription data. ${ }^{28-34}$ The average cost of a visit to an anticoagulation clinic was derived from official sources. ${ }^{28-34}$ The additional cost of international normalised ratio monitoring for each visit was derived from a formal analysis of health care costs in the UK. ${ }^{28}$

\section{Hospital based health care}

The costs of hospital admission and post-discharge outpatient clinic visits during 1995/96 were obtained from an ISD report. ${ }^{34}$

\section{Long term care}

The average weekly cost of resident nursing home care was obtained from a contemporary British report. ${ }^{33}$
Projected cost of AF in $\mathbf{2 0 0 0}$

The most contemporary prevalence estimate for AF in the UK comes from the general practice research database in 1998 (showing a rise from 1994). ${ }^{4}$ We applied the 1998 prevalences for AF to the British population in the year 2000 on an age and sex specific basis (with a $10 \%$ reduction to remain conservative).

For the largest component of health care expenditure (hospital stay), we assumed that the observed trends in hospitalisation rates between 1990 and 1995 (and their associated in-patient case fatality rates) ${ }^{16}$ would remain constant for the period 1995-2000. Updated costs were used where available ${ }^{28-34}$ or adjustments made in keeping with changes in the rate of inflation. ${ }^{35}$ Table 1 summarises the costs used for 1995 and 2000.

\section{Sensitivity analyses (2000 cost estimates)}

Because of uncertainties surrounding some of our estimates (for example, the number of hospital admissions), probable changes in treatment practice in the near future, and other factors (such as prevalence), one way sensitivity analyses were undertaken for the year 2000. Those having a significant effect on the "direct" cost of AF were as follows:

- A higher prevalence of AF (10\% greater)

- A greater number of hospital of admissions where AF is listed as the principal diagnosis (10\% more or less)

- A higher rate of warfarin prescriptions (50\%) with an associated increase in the number of anticoagulation monitoring visits

- The additional cost of hospital admissions where stroke and heart failure are listed as the principal diagnosis but $\mathrm{AF}$ is listed as a secondary diagnosis. In these cases AF is likely to be a major contributor to the cause of that admission. ${ }^{16}$

\section{RESULTS}

Estimated cost of community based health care General practitioner consultations

About 534000 people (281 000 men and 253000 women) were being treated for AF in the UK in 1995-that is, $0.9 \%$ of the whole population and $5 \%$ of those $\geqslant 65$ years. There were about 590600 male and 984800 female consultations with general practitioners for AF in 1995, costing £29.5 million.

Table 11995 and 2000 costs for atrial fibrillation in the UK

\begin{tabular}{|c|c|c|}
\hline Cost component & 1995 & 2000 \\
\hline \multicolumn{3}{|l|}{ General practitioner consultations } \\
\hline Clinic visit & $£ 15$ & $£ 22$ \\
\hline Domiciliary visit & $£ 52$ & $£ 59$ \\
\hline \multicolumn{3}{|c|}{ General practitioner referred OPD consultations } \\
\hline Cardiology review & $£ 108$ & $£ 120$ \\
\hline \multicolumn{3}{|l|}{ Anticoagulation visits } \\
\hline Clinic visit & $£ 16$ & $£ 19$ \\
\hline International normalised ratio check & $£ 5$ & $£ 7$ \\
\hline \multicolumn{3}{|l|}{ Hospital costs (per diem) } \\
\hline Geriatric unit & $£ 113$ & $£ 127$ \\
\hline General medical unit & $£ 192$ & $£ 220$ \\
\hline Intensive care unit & $£ 1114$ & $£ 1385$ \\
\hline \multicolumn{3}{|l|}{ Post-discharge OPD consultations } \\
\hline Cardiology review & $£ 108$ & $£ 120$ \\
\hline General medical review & $£ 75$ & $£ 84$ \\
\hline \multicolumn{3}{|l|}{ Post-discharge nursing home care } \\
\hline Residential care (per week) & $£ 272$ & $£ 332$ \\
\hline
\end{tabular}

OPD, outpatient department.

$£ 1=\sim € 1.4$ 
Table 2 Estimated number and cost of prescriptions for atrial fibrillation in the UK during 1995 and 2000

\begin{tabular}{llllll}
\hline & 1995 & & & 2000 & \\
\cline { 2 - 3 } Class of drug (\% prescribed) & $\begin{array}{l}\text { Number of } \\
\text { prescriptions } \\
\text { (millions) }\end{array}$ & $\begin{array}{l}\text { Total cost } \\
\text { (£ millions) }\end{array}$ & & $\begin{array}{l}\text { Number of } \\
\text { prescriptions } \\
\text { (millions) }\end{array}$ & $\begin{array}{l}\text { Total cost } \\
\text { (£ millions) }\end{array}$ \\
\hline Cardiac glycosides (60\%) & 2.24 & $£ 1.17$ & 2.52 & $£ 1.99$ \\
Aspirin (50\%) & 1.97 & $£ 1.53$ & & 2.10 & $£ 1.76$ \\
Warfarin (30\%) & 1.12 & $£ 3.58$ & & 1.28 & $£ 5.40$ \\
Antiarrhythmics (25\%) & 0.94 & $£ 13.8$ & 1.07 & $£ 15.75$ \\
Total & 6.17 & $£ 20.1$ & 6.97 & \\
\hline
\end{tabular}

General practitioner referrals to hospital outpatient clinics

We assumed that one quarter of patients with AF (about 134000 people) attended for an average of two hospital outpatient visits in 1995, costing $£ 28.8$ million.

\section{Drug prescriptions}

Table 2 shows the number and cost of prescriptions for AF. The total cost of the pharmacological management of AF (excluding anticoagulant treatment and monitoring) was $£ 22.0$ million. The additional cost of monitoring the $30 \%$ of patients prescribed warfarin was $£ 26.9$ million (this includes
1.28 million anticoagulant clinic visits). The total cost of drug treatment for AF in 1995 was, therefore, £48.9 million.

\section{Estimated cost of hospital based care}

Hospital admissions (principal diagnosis)

There were about 31000 hospitalisations in 1995, involving 26000 men, associated with a principal diagnosis of AF (these accounted for a total of 193000 bed-days). For women, the equivalent figures were 28000 hospitalisations, 24000 people, and 159000 bed-days. Figure 1 shows the outcome of the patients who were hospitalised. By stratifying costs according to the proportion of bed-days spent in different types of wards

Male patients

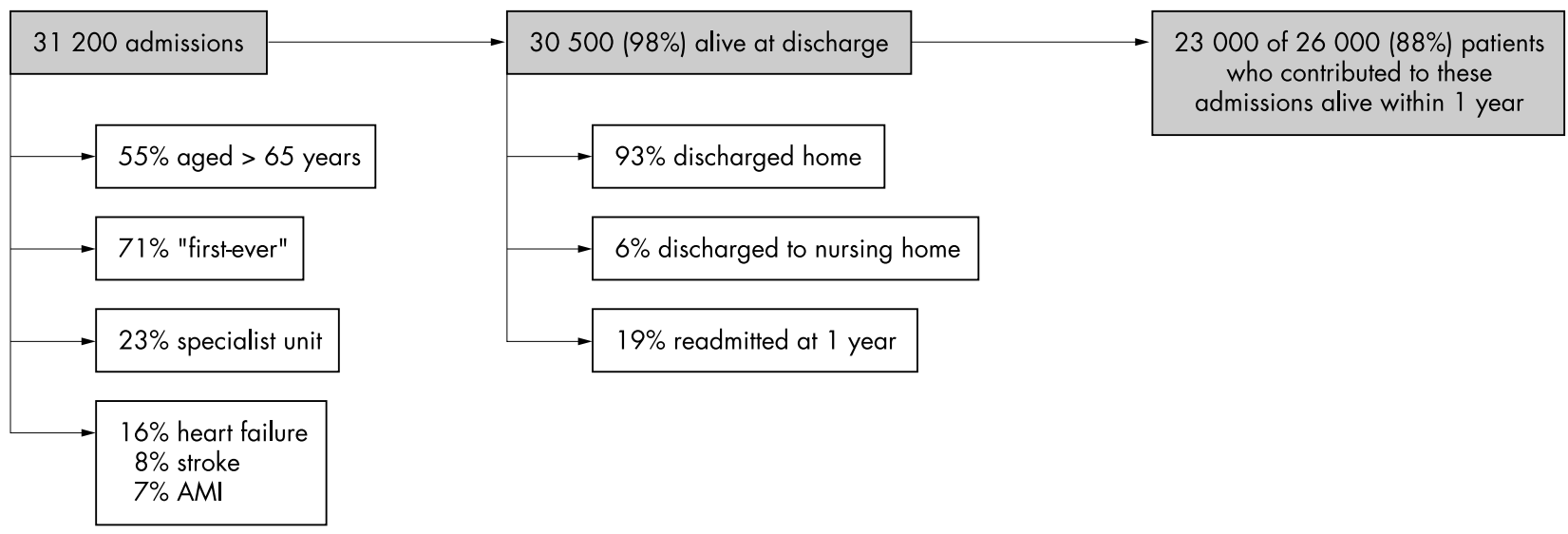

Female patients

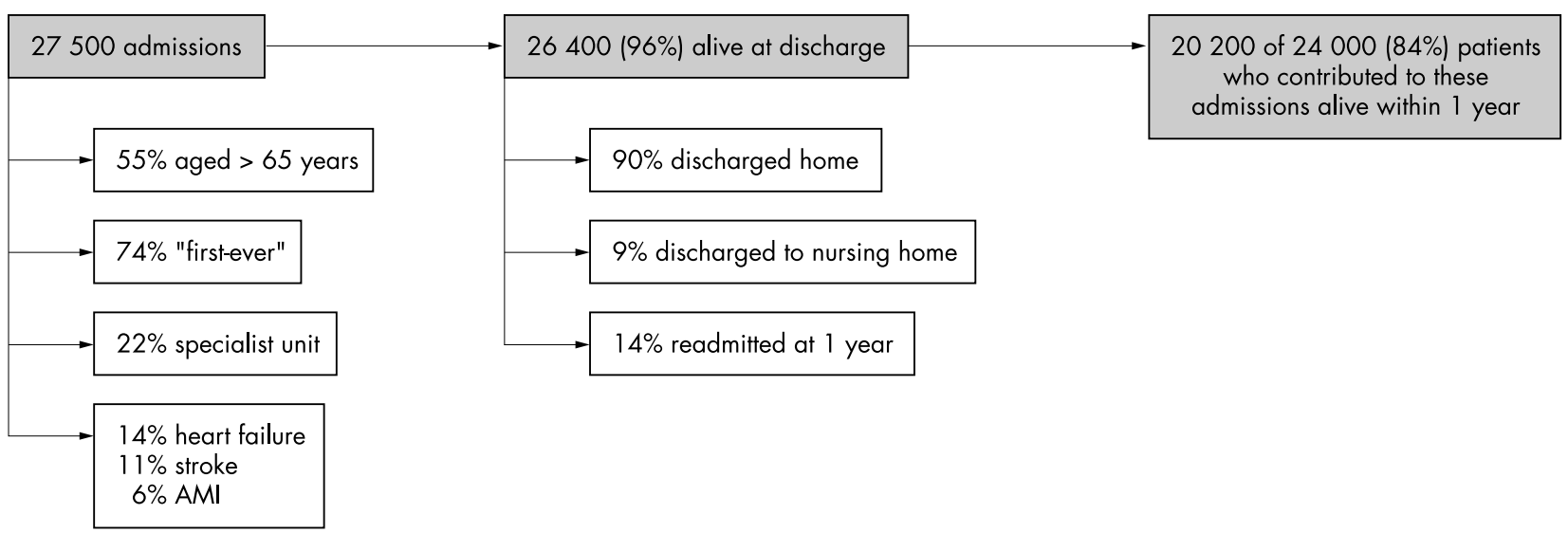

Figure 1 Profile of hospitalisations associated with a principal diagnosis of atrial fibrillation in 1995 and subsequent outcomes. AMl, acute myocardial infarction. 
(general or specialty), we calculated that the total expenditure on AF hospitalisations was £121.7 million in 1995.

The greatest expenditure was for men aged 55-64 years (£20.6 million) and for women aged $75-84$ years $(£ 17.1$ million).

\section{Postdischarge outpatient visits}

There were 29000 and 24000 discharges involving "live" men and women, respectively, associated with a principal diagnosis of AF not resulting in long term care in 1995. Assuming an average of three follow up visits for each admission, the total expenditure for this component of health care was calculated to be $£ 15.0$ million ( $£ 8.2$ million for men and $£ 6.8$ million for women).

\section{Additional hospital admissions (secondary diagnosis)}

There were a further 60000 hospitalisations for men (involving 46000 men and 450000 bed-days) associated with a secondary coding for AF in 1995. For women, the equivalent figures were 69000 hospitalisations, 55000 women, and 440000 bed-days. The total cost of these admissions to the NHS was $£ 240.9$ million ( $£ 128.3$ million for men and £112.6 million for women).

\section{Long term nursing home care}

About 1900 men and 2500 women were discharged to a nursing home after a hospital admission associated with a principal diagnosis of AF in 1995. These patients needed 1.2 million days of residential care in 1995, costing £18.9 million for men and $£ 27.5$ million for women.

\section{Total AF related health care expenditure in 1995}

AF cost the NHS a total of $£ 243.9$ million in 1995 (excluding hospitalisations with a secondary coding of AF and postdischarge nursing home care) (figs 2 and 3). In the same year, the total NHS expenditure was £39 118 million-AF accounted for about $0.62 \%$ of this expenditure. The major component of this expenditure was hospital admissions (50\% of the total and $0.31 \%$ of the total NHS budget). This is an underestimate of the true cost of AF related hospitalisations because of the many other hospitalisations associated with a secondary coding of AF. These cost an additional £241 million or $0.62 \%$ of NHS expenditure. The second largest component of overall cost was drug treatment (accounting for 20\%), particularly anticoagulant treatment and monitoring.

\section{Projected cost of AF in 2000}

\section{Community based care}

By 2000 an additional 67000 people required treatment for AF-that is, a total of 601149 people, over $1 \%$ of the population. Corresponding increases in the numbers of general practitioner consultations and general practitioner referrals to hospital outpatient clinics were estimated to cost $£ 49.8$ million and $£ 36.4$ million, respectively. The cost of drug prescriptions (including the cost anticoagulant clinic visits) increased to $£ 69.5$ million.

\section{Hospital based care}

There were about 109000 admissions for men and women (for 663000 hospital bed-days) associated with a principal diagnosis of AF during 2000. This cost increased by $123 \%$ from $£ 121.7$ million in 1995 to $£ 271.6$ million in 2000 ( $£ 152.1$ million for men and $£ 119.5$ million for women admitted in 2000). The number of post-discharge outpatient visits increased to $£ 31.7$ million and the cost of nursing home care rose from $£ 46.4$ million in 1995 to $£ 110.7$ million in 2000 . Because of the even greater rise in hospitalisations with a secondary diagnosis of $\mathrm{AF}$, the cost of these admissions increased to $£ 726.6$ million in the year 2000 .

Total AF related expenditure in 2000

The direct cost of AF during 2000 (excluding hospitalisations with a secondary AF coding and nursing home costs) was $£ 459.0$ million, a $56 \%$ increase above that of inflation, compared with 1995 and $0.88 \%$ of total NHS expenditure (fig 3).

\section{Sensitivity analyses}

Figure 4 summarises the results of the sensitivity analyses.

\section{DISCUSSION}

Although AF is the most common chronic cardiac arrhythmia, ${ }^{1-4}$ a well recognised cause of cardiovascular morbidity, ${ }^{10-12}$ and an increasingly common cause of hospital admission, ${ }^{12-20}$ the cost of this condition to a health care system has never been quantified. The recent availability of large relevant datasets has now made this exercise feasible. We found that the direct cost of AF to the NHS in the UK was between $£ 244$ and $£ 531$ million (or $0.6-1.2 \%$ of overall health care expenditure in the UK) in 1995. We also found that the cost of AF rose greatly between 1995 and 2000. In 2000 the direct cost of AF was $£ 459$ million-almost double that in 1995. Overall, AF accounted for $0.9-2.4 \%$ of NHS expenditure in 2000 (or $1-2.7 \%$ of NHS expenditure on the basis of 1995 levels of funding). These are almost certainly conservative estimates since additional costs, such as those related to stroke rehabilitation, digoxin toxicity, and warfarin or aspirin related haemorrhage, have not been considered. A minimum of an additional $£ 111$ million was also spent on admission to nursing homes.

The range of the estimated cost of AF to the NHS may, at first sight, seem wide. This, however, reflects the difficulty in determining whether AF contributed directly to hospital

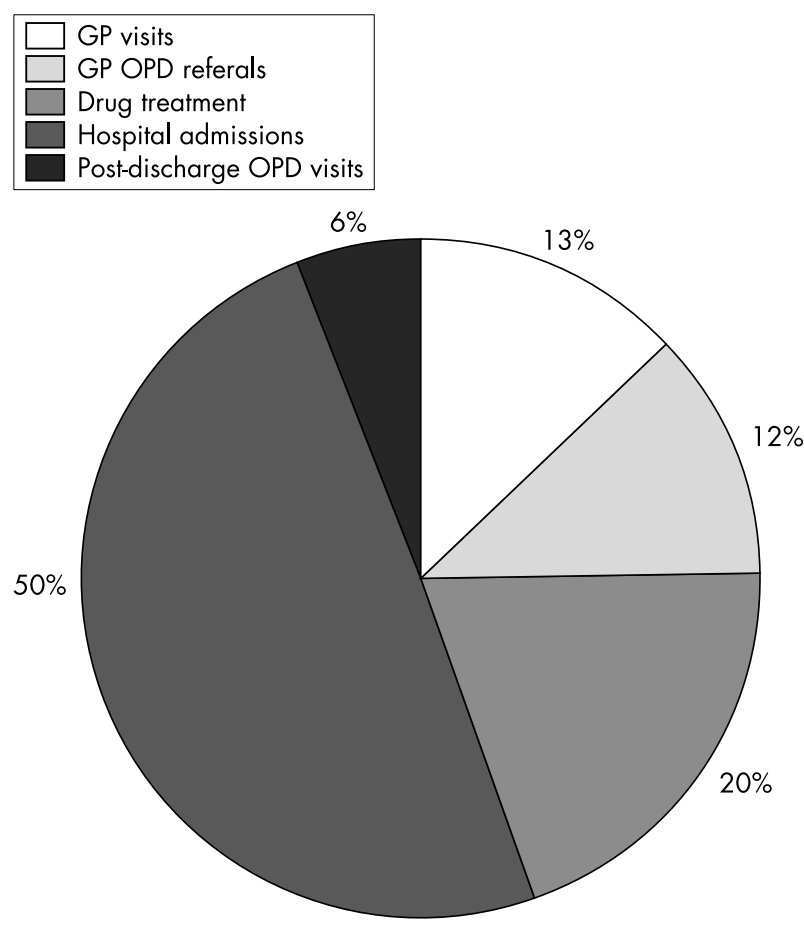

Figure 2 Components of health care expenditure related to atrial fibrillation in the UK in 1995 (excluding secondary admissions and long term nursing home care. GP, general practitioner; OPD, outpatient department. 
$\mathrm{GP}=$ General Practitioner $\mathrm{m}=$ millions OPD = Outpatient department

* Total cost if nursing home care and secondary admissions included

Year 1995

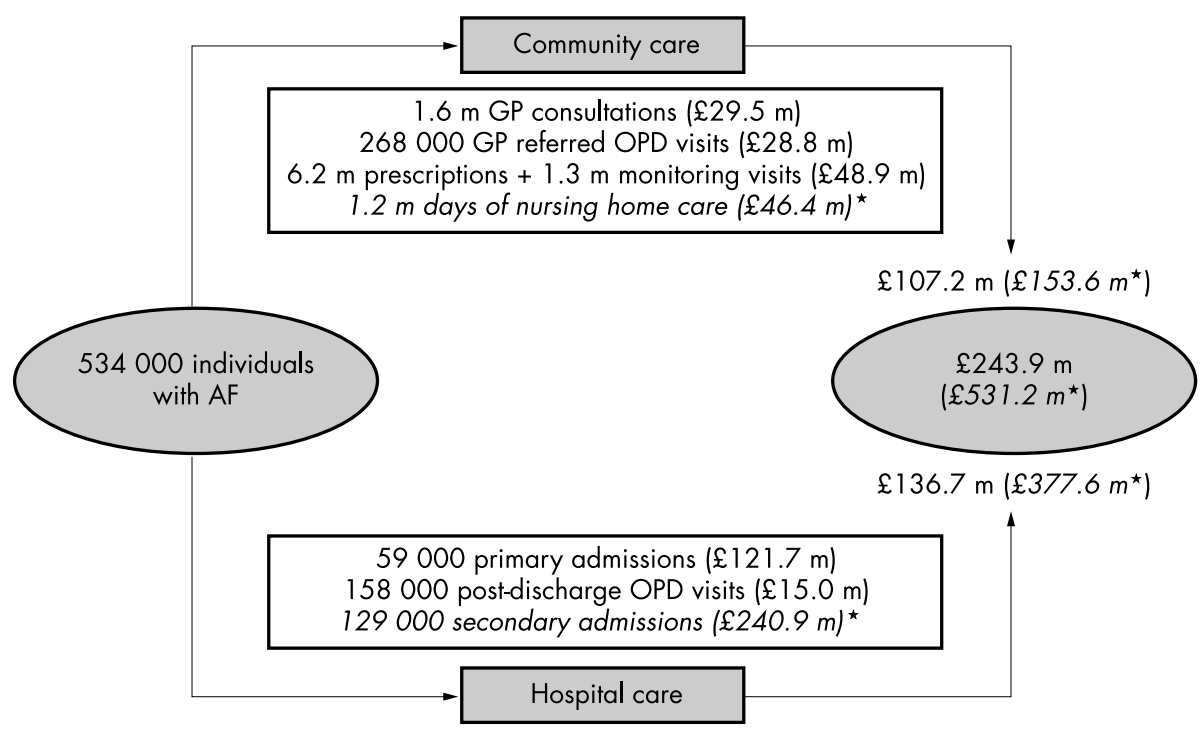

Year 2000

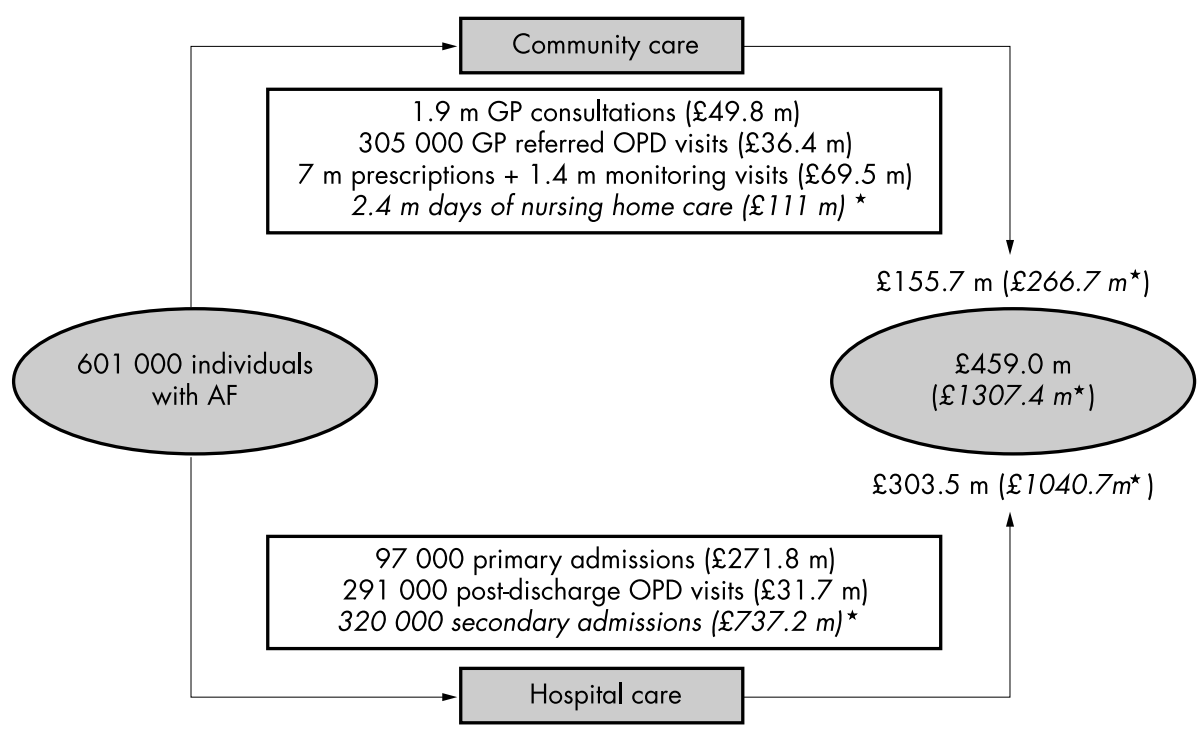

Figure 3 Comparison of the projected burden of atrial fibrillation (AF) in the UK in 1995 versus 2000. m, millions. *Total cost if nursing home care and secondary admissions included. admissions. The most conservative approach, counting only hospitalisations where AF was the principal discharge diagnosis, almost certainly underestimates the true cost of this condition. For example, in the case of heart failure or stroke caused by AF, AF would commonly be coded in a secondary position. Sensitivity analysis shows that these admissions cost an additional £221 and £228 million, respectively. Costing all hospitalisations where AF is coded at discharge provides an upper limit for the potential economic burden of this condition. The same considerations also apply to nursing home occupancy.

To provide a perspective, prior analyses that we have done using identical methods have estimated the direct costs of heart failure ${ }^{14}$ and angina ${ }^{19}$ to the NHS to be $£ 1000$ and $£ 668$ million, respectively. Other analyses, using similar approaches, have calculated the cost of health care expenditure in the UK for stroke (where a proportion of the cost must relate to AF), diabetes, and epilepsy. Up-rated to 2000, these are estimated to cost $£ 1100$ million, $^{36} £ 900$ million, ${ }^{37}$ and $£ 190$ million, ${ }^{38}$ respectively.

The pattern of expenditure for a given disease often indicates targets for therapeutic intervention aimed at reducing costs-that is, it identifies potentially cost effective treatment. As with other common, chronic cardiovascular problems, the majority of AF expenditure reflects frequent, recurrent, and often prolonged hospital admissions (indeed the rapid increase in cost of AF largely reflects rapidly increasing numbers of hospitalisations for this condition). Here, however, AF is less well understood than other cardiovascular problems. The factors leading to hospital 


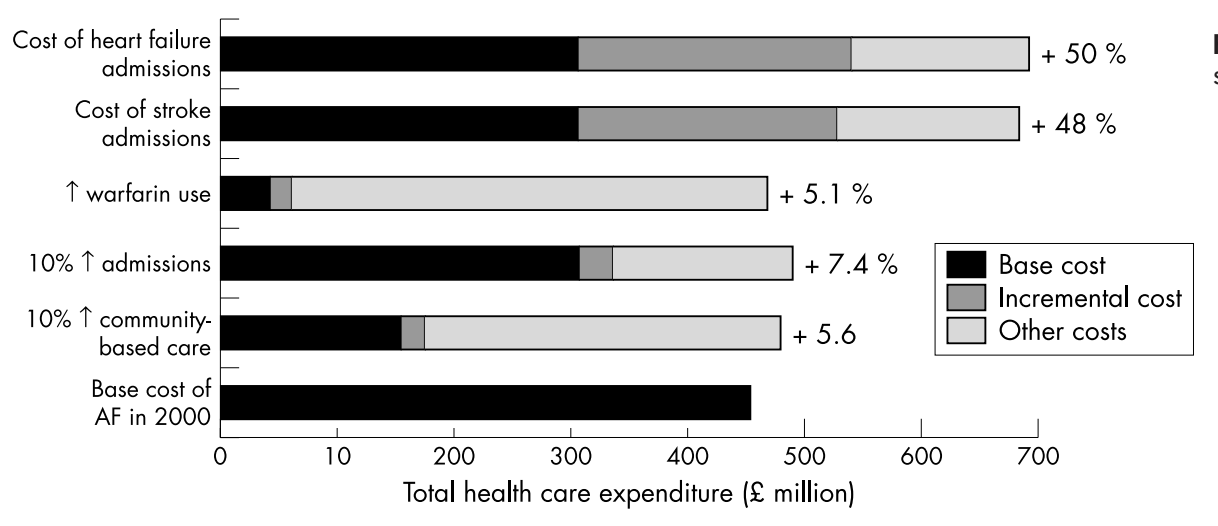

Figure 4 Summary of one way sensitivity analyses.

admission related to AF have not been fully elucidated. Consequently, avoidance of hospital admission and cost containment are equally poorly understood. One relation is, however, well recognised-that of AF and stroke. The risk of stroke can be substantially reduced with warfarin, though this treatment is underused in practice. ${ }^{24}{ }^{39}$ For example, even a modest $15 \%$ reduction in stroke related AF admissions would reduce the cost related to AF by $£ 30$ million a year. Clearly, a further reduction in AF related morbidity and costs requires a much better understanding of the relation between $\mathrm{AF}$ and heart failure, ${ }^{11}$ another major contributor to $\mathrm{AF}$ related hospital bed-days.

This study, like any other of its kind, has certain limitations. Some of these have been described above. One not discussed is the extrapolation of Scottish rates of general practitioner consultation and hospitalisation rates to the UK as a whole. The prevalence of heart disease is higher in Scotland than in some parts of England (a greater socioeconomic gradient in heart disease related events in Scotland being an important consideration); hence, our data may inflate the overall cost of AF marginally in the UK. Conversely, we could not calculate the cost of accident and emergency visits not leading to hospital admission. We know of no source of accurate data on such visits. We have also not been able to take account of new interventional (pacing and ablation) and surgical approaches to the treatment of $\mathrm{AF}$, as reliable information is not available. Moreover, because reliable information is unavailable, we were also unable to calculate the indirect costs (for example, related to loss of employment) of $\mathrm{AF}$, which are also likely to be substantial.

Despite these limitations, we have shown that this insidious and deadly arrhythmia imposes a substantial economic as well as a health burden on the NHS in the UK (this is also likely to be true of other countries, given that the morbidity related to $\mathrm{AF}$ and the treatment of $\mathrm{AF}$ are comparable and that these are the major drivers of cost). Moreover, it is clear that AF related costs are escalating rapidly and that AF is worthy of the attention directed towards heart failure when it became clear the latter was becoming a major public health problem. ${ }^{40}$ Most of the cost of AF relates to hospital admissions, and cost containment will require measures to reduce the risk of hospitalisation. At present, the factors leading to such hospitalisations are poorly understood.

\section{ACKNOWLEDGEMENTS}

SS is supported by the NHMRC and the NHF of Australia; NM is supported by the British Heart Foundation.

\section{Authors' affiliations}

S Stewart, Division of Health Sciences, the University of South Australia, Adelaide, Australia

N Murphy, J J V McMurray, Department of Cardiology, Western

Infirmary, Glasgow, UK

A Walker, Robertson Centre for Biostatistics, the University of Glasgow, Glasgow, UK

A McGuire, Department of Health and Social Care, the London School of Economics, London, UK

\section{REFERENCES}

1 Ezekowitz MD. Atrial fibrillation: the epidemic of the new millennium. Ann Intern Med 1999; 131:537-8.

2 Ryder KM, Benjamin EJ. Epidemiology and significance of atrial fibrillation. Am J Cardiol 1998;84:131R-8R

3 Sudlow M, Thomson R, Thwaites B, et al. Prevalence of atrial fibrillation and eligibility for anticoagulants in the community. Lancet 1998;352:1167-71.

4 Majeed A, Moser K, Carroll K. Trends in the prevalence and management of atrial fibrillation in general practice in England and Wales, 1994-1998: analysis of data from the general practice research database. Heart 2001;86:284-8.

5 Butler RN. Population aging and health. BMJ 1997;315:1082-4.

6 Macintyre K, Capewell S, Stewart S, et al. Evidence of improving prognosis in heart failure: trends in case fatality in 66,547 patients hospitalized between 1986 and 1995. Circulation 2000;102:1126-31.

7 Capewell S, Maclntyre K, Stewart S, et al. Age, sex and social trends in out-ofhospital cardiac deaths in Scotland 1986-1995: a retrospective cohort study. Lancet 2001;358:1213-7.

8 Lee $\mathrm{H}$, Alderman MH. Malignant hypertension: declining mortality rate in New York City, 1958 to 1974. N Y State J Med 1978;78:1389-91.

9 Fuster V, Ryden LE, Asinger RW, et al. ACC/AHA/ESC guidelines for the management of patients with atrial fibrillation: executive summary. A report of the American College of Cardiology/American Heart Association task force on practice guidelines and the European Society of Cardiology committee for practice guidelines and policy conferences (committee to develop guidelines for the management of patients with atrial fibrillation) developed in collaboration with the North American Society of Pacing and Electrophysiology. Circulation 2001;104:21 18-50.

10 Ryder KM, Benjamin JL, Shen WK, et al. Epidemiology and natural history of atrial fibrillation: clinical implications. J Am Coll Cardiol 2001;37:371-8.

11 Stewart S, Hart CL, Hole DA, et al. Long term risks associated with atrial fibrillation: 20-year follow-up of the Renfrew/Paisley study. Am J Med 2002; 113:359-64

12 Frost L, Engholm G, Moller H, et al. Decrease in mortality in patients with a hospital diagnosis of atrial fibrillation in Denmark during the period 19801993. Eur Heart J 1999;20:1592-9.

13 Evers SM, Engel GL, Ament AJ. Cost of stroke in the Netherlands from a societal perspective. Stroke 1997;28:1375-81.

14 Stewart S, Jenkins A, Buchan S, et al. The current cost of heart failure in the UK: an economic analysis. Eur J Heart Fail 2002;4:361-71.

15 Wolf $\mathbf{P}$, Mitchell JB, Baker CS, et al. Impact of atrial fibrillation on mortality, stroke and medical costs. Arch Intern Med 1998;158:229-34.

16 Stewart S, Maclntyre K, MacLeod MMC, et al. Trends in hospital activity, morbidity and case fatality related to atrial fibrillation in Scotland, 19861996. Eur Heart J 2001;22:693-701.

17 Carrol K, Majeed A. Trends in mortality and hospital admissions associated with atrial fibrillation in England and Wales. Health Stat Quart $2001 ; 9: 37-44$

18 Stewart S, MacIntyre K, Boyd J, et al. Trends in first-ever admissions for atrial fibrillation in Scotland: 1985-1995. Int J Cardiol 2002;82:229-36.

19 Stewart S, Murphy N, Walker A, et al. The current cost of angina pectoris to the National Health Service in the UK. Heart 2003;89:848-53. 
20 Stewart S, Hart CL, Hole DJ, et al. Population prevalence, incidence and predictors of atrial fibrillation in the Renfrew/Paisley Study. Heart $2001 ; 86: 516-21$

21 Smith WC, Kenicer MB, Tunstall-Pedoe $\mathrm{H}$, et al. Prevalence of coronary heart disease in Scotland: Scottish heart health study. Br Heart $J$ 1990;64:295-8.

22 Milne RM, Taylor MW, Taylor RJ. Audit of populations in general practice: the creation of a national resource for the study of morbidity in Scottish general practice. J Epidemiol Community Health 1998;5(suppl 1):20s-24s.

23 Anon. Royal College of General Practitioners, Office of Population Censuses and Surveys, Department of Health. Morbidity statistics from general practice: fourth national study 1991-1992. London: HMSO, 1995.

24 Howitt A, Armstrong D. Implementing evidence based medicine in general practice: audit and qualitative study of antithrombotic treatment for atrial fibrillation. BMJ 1999;318:1324-7.

25 Kendrick S, Clarke J. The Scottish record linkage system. Health Bull 1993;51:72-9.

26 Harley K, Jones C. Quality of Scottish morbidity record (SMR) data. Health Bull 1996:54:410-7.

27 Anon. Manual of the international statistical classification of diseases, injuries and causes of death, 9th rev. Geneva: World Health Organization, 1977.

28 Netten A, Dennett J, Knight J. Unit costs of health and social care 1998. Canterbury: Personal Social Services Research Unit, University of Kent, 1998.
29 Anon. National Health Service in Scotland. Scottish Health Service Costs 1995/96. Edinburgh: Information and Statistics Division, 1995

30 Prescription Pricing Authority. http://www.ppa.org.uk. Growth in Prescription Volume and Cost Reports (accessed 2000/2001).

31 National Health Service (UK). http://www doh gov uk nhsexec refcosts htm (originally accessed 2000/2001), now available via omni.ac.uk under the heading "Health expenditure/statistics \& numerical data".

32 Anon. 10th Compendium of health statistics. London: Office of Health Economics, 1997

33 Netten A, Rees T, Harrison G. Unit costs of health and social care 2001. Canterbury: Personal Social Services Research Unit, University of Kent, 2001. 34 Anon. National Health Service in Scotland. Scottish health service costs 1999/ 2000. Edinburgh: Information and Statistics Division, 2000

35 Bank of England. http://www.bankofengland.co.uk/inflationreport/ irO0feb.pdf (Inflation report-February 2000, chart 2, p 4).

36 Dale S. Stroke. London: Office of Health Economics, 1989.

37 Laing W. The cost of diet related disease. In: Turner M, ed. Preventative Nutrition Society, London: Academic Press, 1989.

38 Griffin J, Wyles M. Epilepsy: towards tomorrow. London: Office of Health Economics, 1991.

39 Lip GY. Thromboprophylaxis for atrial fibrillation. Lancet 1999;353:1620-1.

40 Morrison C, McMurray JJ. Heart failure: the Cinderella of cardiology? Public Health 1997:111:351-4. 